\title{
Role of aripiprazole in treatment-resistant schizophrenia
}

This article was published in the following Dove Press journal:

Neuropsychiatric Disease and Treatment

22 May 2012

Number of times this article has been viewed

\author{
Nilufar Mossaheb' \\ Rainer M Kaufmann² \\ 'Department of Child and Adolescent \\ Psychiatry, ${ }^{2}$ Department of Psychiatry \\ and Psychotherapy, Medical \\ University, Vienna, Austria
}

\begin{abstract}
About one third of patients with schizophrenia respond unsatisfactorily to antipsychotic treatment and are termed "treatment-resistant". Clozapine is still the gold standard in these cases. However, $40 \%-70 \%$ of patients do not improve sufficiently on clozapine either. In the search for more efficacious strategies for treatment-resistant schizophrenia, drugs with different pharmacological profiles seem to raise new hopes, but are they valid? The aim of this review was to evaluate the evidence for aripiprazole as a potential strategy in monotherapy or combination therapy for patients with treatment-resistant schizophrenia. The evidence for aripiprazole monotherapy and for the combination of aripiprazole with psychotropics other than clozapine is scant, and no recommendation can be made on the basis of the currently available data. More effort has been made in describing combinations of aripiprazole and clozapine. Most of the open-label and case studies as well as case reports have shown positive effects of this combination on overall psychopathology and to some extent on negative symptoms. Several reports describe the possibility of dose reduction for clozapine in combination with aripiprazole, a strategy that might help so-called "treatment-intolerant" patients. The findings of four randomized controlled trials with respect to changes in psychopathology seem less conclusive. The most commonly found beneficial effects are better metabolic outcomes and indicators of the possibility of reducing the clozapine dose. However, other side effects, such as akathisia, are repeatedly reported. Further, none of the studies report longer-term outcomes. In the absence of alternatives, polypharmacy is a common strategy in clinical practice. Combining aripiprazole with clozapine in clozapine-resistant or clozapine-intolerant patients seems to be worthy of further investigation from the pharmacological and clinical points of view.
\end{abstract}

Keywords: aripiprazole, clozapine, antipsychotic, treatment-resistant schizophrenia

\section{Treatment-resistant schizophrenia and its management challenges}

Schizophrenia is a severe psychiatric disorder with one-year incidence rates of about 15/100,000 persons that affects about 26.3 million people worldwide, ${ }^{1}$ making schizophrenia and schizophrenia-related disorders frequently chronic illnesses. Schizophrenia is among the 20 leading causes of disability, and ranks even higher in low-income countries and in men. ${ }^{1}$ Since the serendipitous discovery of chlorpromazine in the 1950s, antipsychotic drugs have been effective treatments for psychotic symptoms and have reduced hospitalization rates. ${ }^{2}$ The majority of patients with schizophrenia respond adequately to treatment with antipsychotics. ${ }^{3}$ However, more than a third of patients do not respond to conventional first-choice treatments ${ }^{3}$ and are deemed to be "treatment-resistant".
Correspondence: Nilufar Mossaheb Department of Child and Adolescent Psychiatry, Medical University Vienna, Waehringer Guertel 18-20,

1090 Vienna, Austria

Tel +43 I4 04003038

Fax +43 I4 04002793

Email nilufar.mossaheb@meduniwien.ac.at 
There have been repeated debates on the definition of treatment resistance and treatment response, ${ }^{4}$ and trials have inconsistently used one or the other definition. A well known definition of treatment resistance is the one based on the criteria put forward by Kane et al, ie, at least three prior antipsychotic treatments within the previous 5 years at chlorpromazine dosages $\geq 1000 \mathrm{mg} /$ day for at least 6 weeks without sufficient reduction of positive symptoms or lack of a period of good functioning in the last 5 years; additional requirements are moderately severe symptoms as well as lack of improvement with haloperidol $\leq 60 \mathrm{mg} /$ day for at least 6 weeks. ${ }^{5}$ In the available research trials, patients are usually deemed treatment-resistant when 1-3 trials of antipsychotic drugs, each lasting for more than 4-6 weeks at adequate doses, ie, chlorpromazine-equivalent doses of 400-1000 mg/day, have failed to reduce positive symptoms sufficiently. ${ }^{4}$ For clinical decision-making in real-life settings, ${ }^{6}$ several guidelines propose treatment resistance after 2-3 trials, including at least one atypical antipsychotic in adequate dosages for at least $4-6$ or 6-8 weeks ${ }^{7,8}$ without satisfactory clinical improvement, thus taking into account a multidimensional approach of clinical symptoms, psychosocial functioning, and well-being. After that, treatment with clozapine should be considered. ${ }^{7,8}$

Indeed clozapine, the first atypical antipsychotics introduced in the early 1970s, is still the gold standard for patients with schizophrenia whose symptoms do not sufficiently improve on antipsychotic treatment, and its superior efficacy in treatment resistance is well documented. ${ }^{2,9,10}$ However, about $40 \%-70 \%$ of patients with treatment-refractory schizophrenia do not respond fully, even to clozapine. ${ }^{11}$ Further, its general use, especially at effective dosages, can be limited by a series of relevant to the point of life-threatening side effects, such as sedation, sialorrhea, metabolic disturbances, weight gain, emerging obsessive-compulsive symptoms, agranulocytosis, cardiomyopathy, and delirium or seizures, ${ }^{12}$ thereby introducing a further subgroup of seemingly treatment-resistant patients, ie, those who are treatmentintolerant. Other important factors that might be related to insufficient response are comorbid substance misuse, inadequate duration of treatment, and inadequate dosage. ${ }^{13}$ Also, with discontinuation rates for antipsychotic medications of 74\% after 18 months in the CATIE (Clinical Antipsychotic Trials of Intervention Effectiveness) study ${ }^{14}$ and up to $90 \%$ after one year in a later study, ${ }^{15}$ nonadherence or diminished treatment adherence, reflecting patient satisfaction, acceptability, quality of life, and insight, have to be taken into account as one further reason for insufficient responses. ${ }^{16-18}$
Potential nonfatal side effects associated with clozapine such as hypersalivation, weight gain, and sedation may even foster lower adherence rates, as well as increased issues of (self-) stigmatization, low self-esteem, and relapse.

A recently published overview of systematic reviews evaluated the effectiveness and safety of different antipsychotics in treatment-resistant schizophrenia, ${ }^{19}$ and concluded that the main advantage of atypical antipsychotics lies in their more favorable safety profile, which might also increase adherence to treatment. In the same vein, combination therapy of antipsychotics might also be useful, to the point of superiority of antipsychotic polypharmacy suggested for specific patient groups. ${ }^{20}$ Indeed, a meta-analysis by Taylor et al conveyed evidence for a modest effect of augmenting clozapine with a second antipsychotic without significant losses in tolerability in the short term. However, important considerations, such as long-term effects and the choice of antipsychotics, are still uncertain, ${ }^{21}$ and clear evidence favoring one adjunctive strategy over another are still scarce. ${ }^{22}$

In the search for other strategies to treat treatmentresistant schizophrenia, drugs with unique pharmacological profiles such as aripiprazole raise new hopes, but are they valid? The aim of this review was to evaluate aripiprazole, its advantages and pitfalls as a potential strategy in monotherapy or combination therapy for patients with treatment-resistant schizophrenia.

\section{Rationale for aripiprazole in treatment-resistant schizophrenia Pharmacology}

Among the currently available antipsychotic drugs, aripiprazole shows a unique pharmacological profile. Via its partial agonism, it binds with high affinity to dopaminergic $\mathrm{D}_{2}$ and $\mathrm{D}_{3}$ receptors and serotonergic $5-\mathrm{HT}_{1 \mathrm{~A}}$ receptors, and acts as an antagonist at $5-\mathrm{HT}_{2 \mathrm{~A}}$ and $5-\mathrm{HT}_{2 \mathrm{C}}$ receptors. ${ }^{23,24}$ Unlike other antipsychotic drugs, the affinity of aripiprazole for muscarinergic and histaminergic $\mathrm{H}_{1}$ receptors is low. Strong dopamine $\mathrm{D}_{2}$ blockade and activity at the serotonin receptors as well as at postsynaptic $\mathrm{D}_{2}$ receptors might be responsible for its efficacy in reducing positive and somewhat negative symptoms, respectively. ${ }^{25}$

Early clinical trials of aripiprazole in schizophrenic patients have shown antipsychotic efficacy comparable with that of risperidone or haloperidol. ${ }^{26-30}$ In a recent Cochrane review of 2595 patients included in nine randomized controlled trials (RCT) on the efficacy of aripiprazole versus placebo in schizophrenia and schizophrenia-like psychoses, a significant benefit of aripiprazole was found for short-term 
and medium-term relapse rates and compliance with the protocol. However, insufficient data were available to assess relevant outcome variables, such as death, general, cognitive and economic outcomes, engagement with the service, and patient satisfaction. ${ }^{31}$ Reviewing four trials including 1404 patients for the Cochrane database, Komossa et al reported on the efficacy and tolerability of aripiprazole compared with olanzapine and with risperidone. ${ }^{32}$ Aripiprazole was shown to be less effective than olanzapine but equal to risperidone in improving general mental state. With respect to side effects, patients on aripiprazole showed fewer side effects, such as cholesterol increase and weight gain, sedation and prolactinassociated side effects compared with olanzapine, and less dystonia, fewer QTc interval abnormalities, and a smaller prolactin and cholesterol increase compared with risperidone. On the other hand, more patients on aripiprazole experienced tremor than those on risperidone. ${ }^{32}$ However, with patients leaving the trials early at a rate of $38.5 \%$, the validity of these findings could be questioned. In another systematic review, 78 RCT with atypical antipsychotics including 13,558 patients were evaluated, and olanzapine was found to have superior efficacy compared with aripiprazole, quetiapine, risperidone, and ziprasidone, while risperidone was found to be superior to quetiapine and ziprasidone, and clozapine at dosages $>$ $400 \mathrm{mg}$ /day were more efficacious than risperidone. ${ }^{33} \mathrm{Com}-$ parison with typical antipsychotics confers a clear advantage for aripiprazole with respect to side effects, with comparable efficacy for symptomatic improvement in a further review of nine RCT including 3122 patients with schizophrenia. ${ }^{34}$

\section{Advantages of aripiprazole}

A lower propensity for extrapyramidal side effects, sedation, weight gain, hyperprolactinemia, and other potential side effects can be deduced from the pharmacological profile of aripiprazole. Treatment of schizophrenia with aripiprazole has been shown to induce fewer side effects compared with treatment using first-generation antipsychotics ${ }^{34}$ as well as with olanzapine and risperidone with regard to metabolic, prolactin-related, and dystonic side effects or QTc prolongation. ${ }^{32,35}$ Conversely, switching treatment to aripiprazole could reduce weight gain under olanzapine or clozapine according to a recent meta-analysis including 784 patients. However, mean weight reduction was modest $(-2.55 \pm 1.5 \mathrm{~kg}) .{ }^{36}$ Other groups have found similar tendencies towards weight gain for aripiprazole and other antipsychotics, such as perphenazine in treatment-resistant patients ${ }^{37}$ and risperidone in patients termed "chronic" or suffering from their first schizophrenic episode. ${ }^{38} \mathrm{~A}$ critical review concludes that the potential advantages of aripiprazole with respect to weight changes are still conflicting and need confirmation in a larger sample. ${ }^{39}$ In a clinical practice analysis, aripiprazole, quetiapine, and amisulpride did not carry an increased risk of diabetes mellitus. ${ }^{40}$ In a head-to-head meta-analysis of the metabolic side effects of second-generation antipsychotics in RCT, aripiprazole (like amisulpride) showed intermediate or low elevations in weight, cholesterol, and glucose levels in comparison with other second-generation antipsychotics. ${ }^{41}$ A meta-analysis comparing amisulpride, aripiprazole, olanzapine, quetiapine, risperidone, sertindole, and ziprasidone found aripiprazole to be a second-generation antipsychotic with a statistically significant lower risk and lower mean change in QTc interval. ${ }^{42}$

Further to these effects, adding aripiprazole, a partial dopamine agonist, to a strong dopamine agonistic antipsychotic such as haloperidol has been shown to reverse hyperprolactinemia and associated menstrual disturbances in a highly significant number of patients compared with placebo. ${ }^{43}$ The industry-sponsored STAR (Schizophrenia Trial of Aripiprazole) study revealed improvement in sexual dysfunction with aripiprazole, in addition to decreases in prolactin levels. ${ }^{44}$

The relatively fewer metabolic side effects might be one of the reasons explaining the recent finding by Azekawa et al of a significantly longer time to discontinuation of treatment compared with olanzapine, risperidone, and blonanserin in patients with schizophrenia and schizoaffective disorder. ${ }^{45}$ This is of great relevance because nonadherence and early discontinuation of treatment can be in a causal relationship with supposed treatment resistance. However, within 12 months, no significant difference in discontinuation rates between aripiprazole, chlorpromazine, clozapine, sulpiride, risperidone, olanzapine, and quetiapine was demonstrated in a large Chinese multicenter study, all percentages being around $40 \% .^{17}$

Studies have shown beneficial effects of aripiprazole on negative symptoms, but without superiority over other second-generation antipsychotics; $;^{37,46}$ albeit a lack of an improvement in negative symptoms in general, in a small pilot study, aripiprazole-treated patients with schizophrenia significantly improved on anhedonia and subjective well being scores compared with those on risperidone. ${ }^{47}$

It is well known that obsessive-compulsive symptoms in schizophrenia can be worsened by atypical antipsychotics like olanzapine or clozapine. ${ }^{48}$ Recently, aripiprazole has been shown to improve these symptoms, but sample sizes were very small or of a case report nature. ${ }^{49-54}$ Nevertheless, newly 
emergent obsessive-compulsive symptoms during treatment with aripiprazole have also been reported in two cases. ${ }^{55}$

\section{Problems with aripiprazole}

Notwithstanding the abovementioned safety benefits of aripiprazole, this antipsychotic may also pose new problems, in addition to those known from other antipsychotics. Adverse effects such as nausea, insomnia, and agitation have a higher occurrence rate with aripiprazole compared with typical antipsychotics and with placebo. ${ }^{31,34}$ Recently published adverse effects at a single case report level are rhabdomyolysis ${ }^{56}$ and transient myopia. ${ }^{57}$

\section{Extrapyramidal symptoms and akathisia}

In early industry-sponsored clinical trials, aripiprazole showed slightly more extrapyramidal symptoms and akathisia compared with placebo, but less than for haloperidol or risperidone. ${ }^{58}$ Later, there were several reports of general extrapyramidal symptoms, ${ }^{59-61}$ acute dystonic reactions, ${ }^{62-65}$ and tardive dyskinesia ${ }^{66}$ in patients on treatment with aripiprazole. On the other hand, in some cases, treatment with aripiprazole led to improvements in antipsychotic-induced tardive dyskinesia. ${ }^{67,68} \mathrm{~A}$ commonly reported side effect of treatment with aripiprazole is akathisia. A recent review of clinical trials assessing the occurrence of akathisia in patients with schizophrenia and schizoaffective disorders reported mild to moderate akathisia in 9\% of aripiprazole-treated and $6 \%$ of placebo-treated patients, $12.5 \%$ of aripiprazole-treated versus $24 \%$ of haloperidol-treated patients, and $11 \%$ of aripiprazole-treated versus $6 \%$ of olanzapine-treated patients. However, discontinuation due to akathisia was low, with $0.3 \%$ for aripiprazole versus $0 \%$ for placebo, $0.9 \%$ for aripiprazole versus $2.3 \%$ for haloperidol, and $1.2 \%$ for aripiprazole versus $0.2 \%$ for olanzapine. This analysis did not reveal compromise in clinical response due to treatment-emergent akathisia. ${ }^{69}$ However, it should be noted that in everyday clinical practice it is not always easy to distinguish clearly whether agitation, worsening of psychotic symptoms, and akathisia are side effects of medication or inherent in the acute illness. A number of management strategies for akathisia occurring with second-generation antipsychotics have been reported, with different levels of evidence. ${ }^{70,71}$

\section{Exacerbation of psychosis}

\section{and induction of manic episodes}

Several clinical reports describe exacerbations of psychotic symptoms either on treatment with aripiprazole or during addon therapy with aripiprazole to different antipsychotic; ${ }^{72,73}$ the hypothesis being that dopamine agonism by aripiprazole during a hypodopaminergic state occurring with concomitantly prescribed antipsychotics may lead to exacerbation of positive psychotic symptoms. ${ }^{72,74-79}$ Another rarely reported but important adverse event is drug-induced mania. Until now, very few cases have been described, but the potential ability of aripiprazole to precipitate manic episodes is a noteworthy phenomenon that has been described in schizoaffective disorder, ${ }^{80}$ in schizophrenia, ${ }^{81}$ in obsessive-compulsive disorder, ${ }^{82}$ and generalized anxiety disorder. ${ }^{83}$ Although manic reactions seem to be marginal with respect to frequency of occurrence, they might have a biological plausibility and warrant clinical precautions.

\section{Suicidality}

To our knowledge, there are three published reports of increased suicidality after initiation of aripiprazole (one in "psychosis", ${ }^{84}$ one in depression, ${ }^{85}$ and one article published in Dutch, with no English abstract available ${ }^{86}$ ).

\section{Aripiprazole monotherapy in treatment-resistant schizophrenia}

A multicenter, double-blind, randomized study compared the efficacy and safety of aripiprazole with that of perphenazine in 300 patients with treatment-resistant schizophrenia. Treatment resistance was confirmed by 4-6 weeks of openlabel treatment with either olanzapine $10-20 \mathrm{mg} /$ day or risperidone $2-8 \mathrm{mg} /$ day. Insufficient response was noted when improvements in the Positive and Negative Syndrome Scale (PANSS) total score were under $20 \%$ or the Clinical Global Impressions-Severity of Illness score was $\geq 4$. Treatmentresistant patients were eligible to enter a 6-week, double-blind treatment phase receiving either aripiprazole $15-30 \mathrm{mg} /$ day or perphenazine $8-64 \mathrm{mg} /$ day. Although both drug treatments resulted in clinically relevant improvements in total PANSS scores (27\% of patients treated with aripiprazole and $25 \%$ of patients treated with perphenazine were reported as being responders) and in quality of life (36\% of patients treated with aripiprazole versus $21 \%$ of patients treated with perphenazine), patients on aripiprazole exhibited fewer extrapyramidal symptoms and significantly less elevated prolactin levels. ${ }^{37}$ Some of the findings and conclusions of this industry-sponsored study have been criticized, including relatively more patients on aripiprazole than on perphenazine discontinuing the trial for reasons related to adverse effects. ${ }^{87}$ A single case report describes complete symptomatic remission in a young patient with treatment-resistant schizophrenia during the course of a first psychotic episode on treatment 
with high-dose aripiprazole ( $75 \mathrm{mg} /$ day) without occurrence of adverse events. ${ }^{88}$ In summary, the evidence for aripiprazole monotherapy is currently based on one RCT with at least somewhat disputed data interpretation.

\section{Aripiprazole as an alternative to clozapine}

For the various reasons described above, many patients discontinue treatment with clozapine. There is a dearth of studies dealing with the dilemma of discontinuing and switching from clozapine in treatment-refractory schizophrenia. Two articles, including four cases, present precisely the results of switching from clozapine to aripiprazole, one due to lack of satisfactory response, the other three due to treatment intolerance because of neutropenia. The authors describe safe switches and clinically relevant effects with respect to symptom reduction and functioning. ${ }^{89,90}$ No broad conclusions can be drawn from these case series.

\section{Aripiprazole and clozapine}

Although combination of clozapine with another antipsychotic in patients having an unsatisfactory response is common in real-world settings, evidence-based strategies for combination therapy in clozapine-refractory schizophrenia are sparse. In recent years, efforts have been made to ascertain the evidence of such case report-based strategies. A few RCT have focused on the efficacy of combinations of clozapine with risperidone, haloperidol, amisulpride, sulpiride, and aripiprazole. ${ }^{21}$ Combining clozapine, a multireceptor drug with low affinity for the dopamine $\mathrm{D}_{2}$ receptor, and an antipsychotic with antidopaminergic properties follows a comprehensible neurobiological rationale regarding the pharmacodynamics of complementary receptor profiles. Pharmacokinetic interactions between clozapine and aripiprazole, such as effects on plasma levels, are not probable, given that aripiprazole and clozapine are metabolized by different cytochrome P450 (CYP) isoforms, ie, CYP3A4 and CYP2D6 for aripiprazole, and CYP1A2 and to a lesser extent CYP2D6 for clozapine. . $^{91,92}$

Starting off with promising case reports ${ }^{53,93-99}$ and prospective or retrospective clinical observations, ${ }^{100-104}$ a small number of RCT were initiated to analyze the combination of clozapine and aripiprazole in treatment-resistant schizophrenia. ${ }^{105-108}$ Most of the open-label and case studies as well as case reports show positive effects of this combination on overall psychopathology $53,93-95,99,101-104,109$ and on negative symptoms. ${ }^{96,97,99,102,103}$ Several reports describe the possibility of dose reduction for clozapine in combination with aripiprazole, a strategy that might help so-called treatment-intolerant patients. ${ }^{93,98,101,102}$ Indeed, a review of 94 patients in 11 publications reports a clozapine dose reduction from $476.7 \mathrm{mg}$ /day to $425 \mathrm{mg}$ /day alongside an improvement in psychopathology, and a reduction in clozapine-related side effects with mean aripiprazole add-on therapy of $20.5 \mathrm{mg} /$ day. ${ }^{110}$

To our knowledge, four RCT of aripiprazole in clozapinerefractory patients with schizophrenia have been published (see Table 1), ${ }^{105-108}$ three of which were double-blind and placebo-controlled, ${ }^{105,106,108}$ one comparing aripiprazole with haloperidol using blinded raters. ${ }^{107}$ These RCT together included a total of approximately 400 patients. The trial by Fleischhacker et al investigated metabolic parameters as primary outcome variables, but outcome data on psychopathology are also reported. ${ }^{106}$ The findings of these RCT with respect to changes in psychopathology seem less optimistic than those of the case reports and open-label trials. Two trials report no benefits from aripiprazole in combination with clozapine compared with placebo ${ }^{106}$ or with haloperidol. ${ }^{107}$ Improvements in negative symptoms were reported by Chang et al only after secondary analysis ${ }^{105}$ and by Muscatello et al only for alogia ${ }^{108}$ compared with the several promising non$\mathrm{RCT}$ reports mentioned above.

However, it should be noted that most RCT have included patients on stable mean clozapine doses at the lower end of the efficacy range $\left(310.7 \pm 73.1 \mathrm{mg} /\right.$ day ${ }^{108} 383 \pm 158.2 \mathrm{mg} /$ day, ${ }^{106}$ $304 \pm 104.8 \mathrm{mg} /$ day, ${ }^{105} 421 \pm 142 \mathrm{mg} /$ day $^{107}$ ), raising the question of whether patient symptoms were really refractory to treatment or if they were not treated at high enough doses because of intolerance. Furthermore, it is generally recommended to assess the efficacy of clozapine in treatment-resistant patients after a minimum of 3-6 months because delayed improvement is possible. ${ }^{111,112}$ However, RCT have used different inclusion criteria, thereby limiting comparability. For example, in the study by Muscatello et al, patients had to be on clozapine treatment for at least one year, but on a stable dose for a minimum of only one month, ${ }^{108}$ Fleischhacker et al included patients who had been on a stable clozapine dose for a minimum of 3 months, ${ }^{106}$ Chang et al reported on a minimum treatment of one year with at least 2 months at a stable clozapine dose $\geq 400 \mathrm{mg},{ }^{105}$ and, finally, Barbui et al included patients on stable clozapine doses for at least 6 months. ${ }^{107}$

The strongest beneficial effects of adding aripiprazole to clozapine that runs through the findings of the RCT, case reports, and open-label studies combined are better metabolic outcomes and indicators of the possibility for reducing the clozapine dose. However, other side effects, such as akath- 


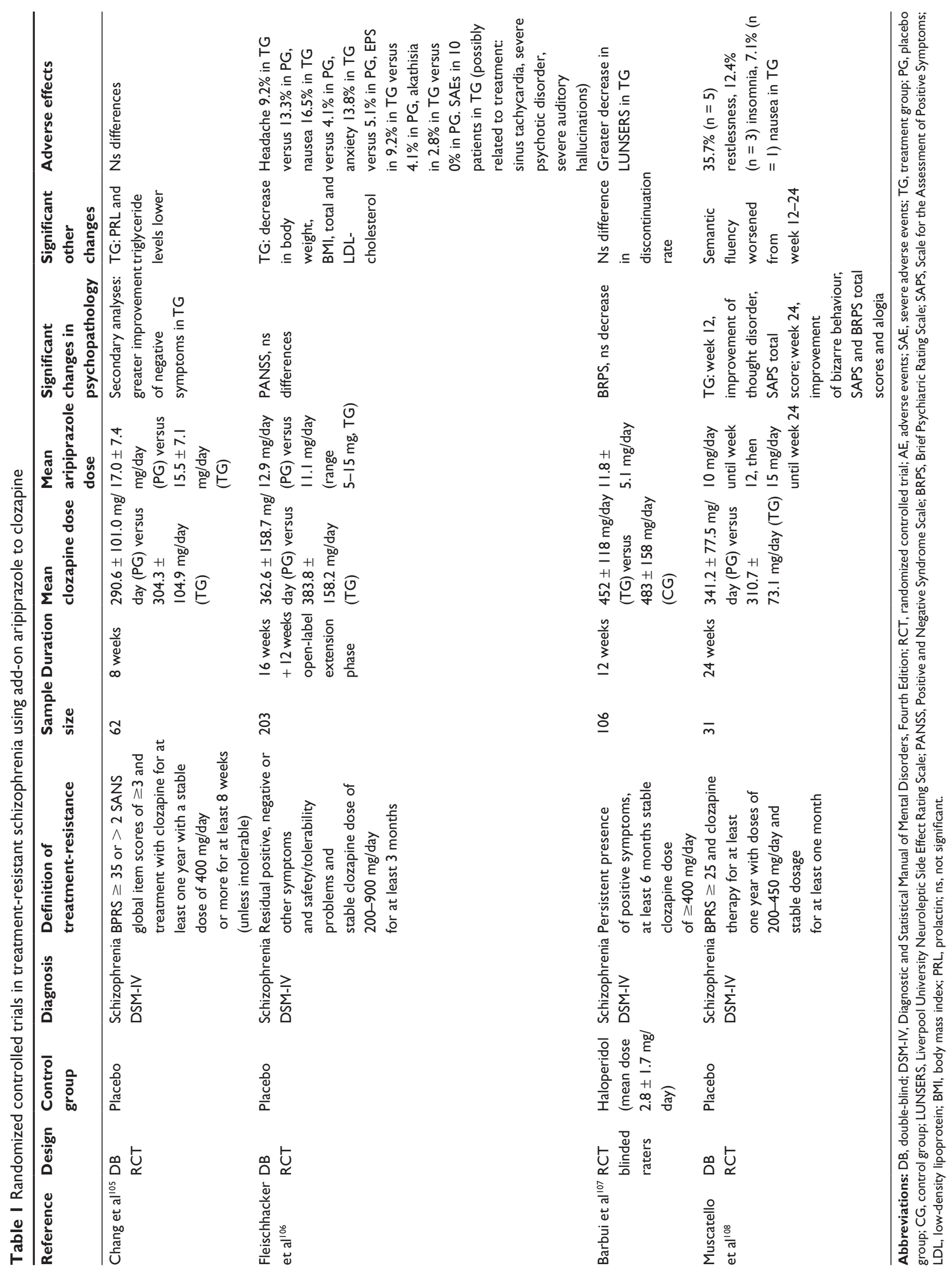


isia, are repeatedly reported. Also, none of the studies report longer-term outcomes. In the light of the sobering results of the CATIE and CUtLASS (Cost Utility of the Latest Antipsychotic Drugs in Schizophrenia Studies) trials. ${ }^{14,113}$ Regarding the presumed superiority of second-generation antipsychotics when effectiveness instead of mere efficacy is assessed as the primary outcome parameter, it is noteworthy that most studies have assessed clinical efficacy but not effectiveness (ie, discontinuation rates).

\section{Aripiprazole and other psychotropics}

Other strategies have to be sought for patients who do not respond adequately to clozapine or its augmentation, or who are clozapine-intolerant. High-level evidence for specific augmentation strategies combining clozapine with other antipsychotics is still rather scant, and even moreso for combinations of antipsychotics other than clozapine. However, in the absence of alternatives, polypharmacy is a common strategy in clinical practice, and encouraged by meta-analytical data favoring antipsychotic combinations over monotherapy in some clinical situations, such as combinations including clozapine, a trial duration of more than ten weeks, and parallel initiation of antipsychotic combinations and combinations of first-generation and second-generation antipsychotics. ${ }^{20}$

Combining aripiprazole with another antipsychotic seems to be worthy of further investigation from a pharmacological point of view, but relevant studies are almost nonexistent. A retrospective case series of combinations of aripiprazole with a wide range of other psychotropics in treatmentresistant patients, including six patients with schizophrenia, reported moderate to adequate improvement and good tolerability. Combinations included risperidone long-acting injection and haloperidol, clozapine, ziprasidone, quetiapine and olanzapine, and quetiapine and risperidone, all of which were augmented with aripiprazole. ${ }^{114}$

In a multicenter RCT of 323 patients with schizophrenia or schizoaffective disorder with a chronic course, but not explicitly termed treatment-resistant, adjunctive administration of aripiprazole $2-15 \mathrm{mg}$ /day with risperidone $4-8 \mathrm{mg}$ /day or quetiapine 400-800 mg/day revealed no significant improvement in psychiatric symptoms assessed by PANSS, but was broadly well tolerated. ${ }^{115}$ No further conclusions can be drawn regarding aripiprazole combined with other psychotropics for treatment-resistant schizophrenia from the available data.

\section{Conclusion}

From the pharmacological and clinical points of view, aripiprazole seems worthy of further investigation for clozapine-resistant and clozapine-intolerant patients. The evidence for aripiprazole monotherapy and for the combination of aripiprazole with psychotropics other than clozapine is scant, and no recommendations can be drawn from the currently available data. More effort has been made in describing combinations of aripiprazole and clozapine. While open-label and case studies show improvement in overall psychopathology and in negative symptoms, results of RCT are inconclusive regarding effects on psychopathology. Given the potential of most antipsychotics to induce deleterious metabolic effects, the repeated finding of a lesser metabolic impact of aripiprazole is noteworthy. This, as well as the potential effects concerning dosage reduction, might be of particular value in patients treated with clozapine. However, other side effects, such as agitation and akathisia, have been repeatedly reported, and others, such as exacerbation of psychosis, seem rare but severe. In summary, in this specific population unresponsive to previous treatment, a combination of clozapine with aripiprazole, as well as other augmentation strategies for clozapine, seem worthy of further exploration. However, given the lack of clearcut evidence for an advantage of antipsychotic polypharmacy in general, no confident recommendations can be made and careful clinical appraisal of the risk-benefit ratio of all options is warranted.

\section{Disclosure}

The authors report no conflicts of interest in this work.

\section{References}

1. World Health Organization. The Global Burden of Disease: 2004 update. Available from: http://www.who.int/healthinfo/global_burden_disease/2004_report_update/en/index.html. Accessed February 16, 2012.

2. Kane JM, Correll CU. Past and present progress in the pharmacologic treatment of schizophrenia. J Clin Psychiatry. 2010;71(9): 1115-1124.

3. Conley RR, Buchanan RW. Evaluation of treatment-resistant schizophrenia. Schizophr Bull. 1997;23(4):663-674

4. Suzuki T, Remington G, Mulsant BH, et al. Treatment resistant schizophrenia and response to antipsychotics: a review. Schizophr Res. 2011;133(1-3):54-62.

5. Kane J, Honigfeld G, Singer J, Meltzer H. Clozapine for the treatment-resistant schizophrenic. A double-blind comparison with chlorpromazine. Arch Gen Psychiatry. 1988;45(9):789-796.

6. Mortimer AM, Singh P, Shepherd CJ, Puthiryackal J. Clozapine for treatment-resistant schizophrenia: National Institute of Clinical Excellence (NICE) guidance in the real world. Clin Schizophr Relat Psychoses. 2010(4);4:49-55.

7. American Psychiatric Association. Practice Guideline for the Treatment of Patients with Schizophrenia, Second Edition. Available from: http:// psychiatryonline. org/content . aspx ?bookid=28\&sectionid $=1665359$. Accessed February 16, 2012

8. National Institute for Clinical Excellence. Schizophrenia: Core Interventions in the Treatment and Management of Schizophrenia in Adults in Primary and Secondary Care. 2009. NICE clinical guideline 82. Available from: http://guidance.nice.org.uk/CG82/NICEGuidance/ pdf/English. Accessed on February 16, 2012. 
9. Wahlbeck K, Cheine M, Essali A, Adams C. Evidence of clozapine's effectiveness in schizophrenia: a systematic review and meta-analysis of randomized trials. Am J Psychiatry. 1999;156(7):990-999.

10. McEvoy JP, Lieberman JA, Stroup TS, et al. Effectiveness of clozapine versus olanzapine, quetiapine, and risperidone in patients with chronic schizophrenia who did not respond to prior atypical antipsychotic treatment. Am J Psychiatry. 2006;163(4):600-610.

11. Cipriani A, Boso M, Barbui C. Clozapine combined with different antipsychotic drugs for treatment resistant schizophrenia. Cochrane Database Syst Rev. 2009;3:CD006324.

12. Nielsen J, Damkier P, Lublin H, Taylor D. Optimizing clozapine treatment. Acta Psychiatr Scand. 2011;123(6):411-422.

13. Barnes TR, McEvedy CJ, Nelson HE. Management of treatment resistant schizophrenia unresponsive to clozapine. Br J Psychiatry. 1996;31 Suppl:31-40.

14. Lieberman JA, Stroup ST, McEvoy JP, et al. Effectiveness of antipsychotic drugs in patients with chronic schizophrenia. $N$ Engl $J$ Med. 2005;353(12):1209-1223.

15. Mullins DC, Obeidat NA, Cuffel BJ, Naradzay J, Loebel AD. Risk of discontinuation of atypical agents in the treatment of schizophrenia. Schizophr Res. 2008;98(1-3):8-15.

16. Lindenmayer JP, Liu-Seifert H, Kulkarni PM, et al. Medication nonadherence and treatment outcome in patients with schizophrenia or schizoaffective disorder with suboptimal prior response. J Clin Psychiatry. 2009;70(7):990-996.

17. Guo X, Fang M, Zhai J, et al. Effectiveness of maintenance treatments with atypical and typical antipsychotics in stable schizophrenia with early stage: 1-year naturalistic study. Psychopharmacology (Berl). 2011;216(4):475-484.

18. Xiang YT, Wang CY, Weng YZ, et al. Predictors of relapse in Chinese schizophrenia patients: a prospective, multi-center study. Soc Psychiatry Psychiatr Epidemiol. 2011;46(12):1325-1330.

19. Melnik T, Soares BG, Puga ME, Atallah AN. Efficacy and safety of atypical antipsychotic drugs (quetiapine, risperidone, aripiprazole and paliperidone) compared with placebo or typical antipsychotic drugs for treating refractory schizophrenia: overview of systematic reviews. Sao Paulo Med J. 2010;128(3):141-166.

20. Correll CU, Rummel-Kluge C, Corves C, Kane JM, Leucht S. Antipsychotic combinations vs monotherapy in schizophrenia: a metaanalysis of randomized controlled trials. Schizophr Bull. 2009;35(2): 443-457.

21. Taylor DM, Smith L, Gee SH, Nielsen I. Augmentation of clozapine with a second antipsychotic - a meta-analysis. Acta Psychiatr Scand. 2012;125(1):15-24.

22. Porcelli S, Balzarro B, Serretti A. Clozapine resistance: augmentation strategies. Eur Neuropsychopharmacol. 2012;22(3):165-182.

23. Burris KD, Molski TF, Xu C, et al. Aripiprazole, a novel antipsychotic, is a high-affinity partial agonist at human dopamine D2 receptors. J Pharmacol Exp Ther. 2002;302(1):381-389.

24. Jordan S, Koprivica V, Chen R, Tottori K, Kikuchi T, Altar CA. The antipsychotic aripiprazole is a potent, partial agonist at the human 5-HT1A receptor. Eur J Pharmacol. 2002;441(3):137-140.

25. Stip E, Tourjman V. Aripiprazole in schizophrenia and schizoaffective disorder: a review. Clin Ther. 2010;32 Suppl 1:S3-S20.

26. Kane JM, Carson WH, Saha AR, et al. Efficacy and safety of aripiprazole and haloperidol versus placebo in patients with schizophrenia and schizoaffective disorder. J Clin Psychiatry. 2002;63(9):763-771.

27. Marder SR, McQuade RD, Stock E, et al. Aripiprazole in the treatment of schizophrenia: safety and tolerability in short-term, placebo-controlled trials. Schizophr Res. 2003;61(2-3):123-126.

28. Kasper S, Lerman MN, McQuade RD, et al. Efficacy and safety of aripiprazole vs haloperidol for long-term maintenance treatment following acute relapse of schizophrenia. Int J Neuropsychopharmacol. 2003;6(4):325-337.
29. Pigott TA, Carson WH, Saha AR, Torbeyns AF, Stock EG, Ingenito GG. Aripiprazole for the prevention of relapse in stabilized patients with chronic schizophrenia: a placebo-controlled 26-week study. J Clin Psychiatry. 2003;64(9):1048-1056.

30. Potkin SG, Saha AR, Kukawa MJ, et al. Aripirazole, an antipsychotic with a novel mode of action, and risperidone vs placebo in patients with schizophrenia and schizoaffective disorder. Arch Gen Psychiatry. 2003;60(7):681-690.

31. Belgamwar RB, El-Sayeh HG. Aripiprazole versus placebo for schizophrenia. Cochrane Database Syst Rev. 2011;8:CD006622.

32. Komossa K, Rummel-Kluge C, Schmid F, et al. Aripiprazole versus other atypical antipsychotics for schizophrenia. Cochrane Database Syst Rev. 2009;4:CD006569.

33. Leucht S, Komossa K, Rummel-Kluge C, et al. A meta-analysis of head-to-head comparisons of second-generation antipsychotics in the treatment of schizophrenia. Am J Psychiatry. 2009;166(2):152-163.

34. Bhattacharjee J, El-Sayeh HG. Aripiprazole versus typical antipsychotic drugs for schizophrenia. Cochrane Database Syst Rev. 2008;3:CD006617.

35. Blonde L, Kan HJ, Gutterman EM, et al. Predicted risk of diabetes and coronary heart disease in patients with schizophrenia: aripiprazole versus standard of care. J Clin Psychiatry. 2008;69(5):741-488.

36. Barak Y, Aizenberg D. Switching to aripiprazole as a strategy for weight reduction: a metaanalysis in patients suffering from schizophrenia. J Obesity. 2011;2011:898013.

37. Kane JM, Meltzer HY, Carson WH Jr, McQuade RD, Marcus RN, Sanchez R; Aripiprazole Study Group. Aripiprazole for treatment-resistant schizophrenia: results of a multicenter, randomized, double-blind comparison study versus perphenazine. J Clin Psychiatry. 2007;68(2):213-223.

38. Alvarez-Jiménez M, González-Blanch C, Crespo-Facorro B, et al. Antipsychotic-induced weight gain in chronic and first-episode psychotic disorders: a systematic critical reappraisal. CNS Drugs. 2008;22(7):547-562.

39. Gentile $\mathrm{S}$. A systematic review of quality of life and weight gain-related issues in patients treated for severe and persistent mental disorders: focus on aripiprazole. Neuropsychiatric Dis Treat. 2009;5:117-125.

40. Kessing LV, Thomsen AF, Mogensen UB, Andersen PK. Treatment with antipsychotics and the risk of diabetes in clinical practice. $\mathrm{Br} J$ Psychiatry. 2010;197(4):266-271.

41. Rummel-Kluge C, Komossa K, Schwarz S, et al. Head-to-head comparisons of metabolic side effects of second generation antipsychotics in the treatment of schizophrenia: a systematic review and meta-analysis. Schizophr Res. 2010;123(2-3):225-233.

42. Chung AK, Chua SE. Effects on prolongation of Bazett's corrected QT interval of seven second-generation antipsychotics in the treatment of schizophrenia: a meta-analysis. J Psychopharmacol. 2011;25(5):646-666.

43. Shim JC, Shin JG, Kelly DL, et al. Adjunctive treatment with a dopamine partial agonist, aripiprazole, for antipsychotic-induced hyperprolactinemia: a placebo-controlled trial. Am J Psychiatry. 2007;164(9):1404-1410.

44. Hanssens L, L'Italien G, Loze JY, Marcus RN, Pans M, Kerselaers W. The effect of antipsychotic medication on sexual function and serum prolactin levels in community-treated schizophrenic patients: results from the Schizophrenia Trial of Aripiprazole (STAR) study (NCT00237913). BMC Psychiatry. 2008;8:95.

45. Azekawa T, Ohashi S, Itami A. Comparative study of treatment continuation using second-generation antipsychotics in patients with schizophrenia or schizoaffective disorder. Neuropsychiatr Dis Treat. 2011;7:691-695.

46. Riedel M, Schennach-Wolff R, Musil R, et al. Neurocognition and its influencing factors in the treatment of schizophrenia - effects of aripiprazole, olanzapine, quetiapine and risperidone. Hum Psychopharmacol. 2010;25(2):116-125. 
47. Liemburg E, Aleman A, Bous J, Hollander K, Knegtering H. An open randomized pilot trial on the differential effects of aripiprazole versus risperidone on anhedonia and subjective well-being. Pharmacopsychiatry. 2011;44(3):109-113.

48. Schirmbeck F, Esslinger C, Rausch F, Englisch S, Meyer-Lindenberg A, Zink M. Antiserotonergic antipsychotics are associated with obsessive-compulsive symptoms in schizophrenia. Psychol Med. 2011;41(11):2361-2373.

49. Glick ID, Poyurovsky M, Ivanova O, Koran LM. Aripiprazole in schizophrenia patients with comorbid obsessive-compulsive symptoms: an open-label study of 15 patients. J Clin Psychiatry. 2008;69(12):1856-1859.

50. Schönfelder S, Schirmbeck F, Waltereit R, Englisch S, Zink M. Aripiprazole improves olanzapine-associated obsessive compulsive symptoms in schizophrenia. Clin Neuropharmacol. 2011;34(6): 256-257.

51. Englisch S, Esslinger C, Inta D, et al. Clozapine-induced obsessivecompulsive syndromes improve in combination with aripiprazole. Clin Neuropharmacol. 2009;32(4):227-229.

52. Peters B, de Haan L. Remission of schizophrenia psychosis and strong reduction of obsessive-compulsive disorder after adding clozapine to aripiprazole. Prog Neuropsychopharmacol Biol Psychiatry. 2009;33(8):1576-1577.

53. Rocha FL, Hara C. Benefits of combining aripiprazole to clozapine: three case reports. Prog Neuropsychopharmacol Biol Psychiatry. 2006;30(6):1167-1169.

54. Zink M, Knopf U, Kuwilsky A. Management of clozapine-induced obsessive-compulsive symptoms in a man with schizophrenia. Aust N Z J Psychiatry. 2007;41(3):293-294.

55. Desarkar P, Das A, Nizamie SH. Aripiprazole-induced obsessivecompulsive disorder: a report of 2 cases. J Clin Psychopharmacol. 2007;27(3):305-306.

56. Chang KY, Wu YF. Aripiprazole-associated rhabdomyolysis in a patient with schizophrenia. J Neuropsychiatry Clin Neurosci. 2011;23(3):E51.

57. Nair AG, Nair AG, George RJ, Biswas J, Gandhi RA. Aripiprazole induced transient myopia: A case report and review of literature. Cutan Ocul Toxicol. 2012;31(1):74-76.

58. Citrome L. A review of aripirazole in the treatment of patients with schizophrenia or bipolar I disorder. Neuropsychiatric Dis Treat 2006;2:427-443.

59. Zacher JL, Hatchett AD. Aripiprazole-induced movement disorder. Am J Psychiatry. 2006;163(1):160-161.

60. De Schutter P, Bouckaert F, Peuskens J. Aripiprazole-induced parkinsonism in a 64-year-old female patient diagnosed with bipolar disorder. Tijdschr Psychiatr. 2011;53(5):299-303. Dutch.

61. Ono S, Suzuki Y, Shindo M, et al. Improvement of tardive dyskinesia and dystonia associated with aripiprazole following a switch to quetiapine: case report and review of the literature. J Clin Pharm Ther. October 24, 2011. [Epub ahead of print.]

62. Desarkar P, Thakur A, Sinha VK. Aripiprazole-induced acute dystonia. Am J Psychiatry. 2006;163(6):1112-1113.

63. Henderson JB, Labbate L, Worley M. A case of acute dystonia after single dose of aripiprazole in a man with cocaine dependence. Am J Addict. 2007;16(3):244.

64. McLaren JL, Cauble S, Barnett RJ. Aripiprazole induced acute dystonia after discontinuation of a stimulant medication. J Clin Psychopharmacol. 2010;30(1):77-78.

65. Solomon S, Gupta S, Jesudasan J. Temporomandibular dislocation due to aripiprazole induced dystonia. Br J Clin Pharmacol. 2010;70(6):914-915

66. Oommen E, Chand PK, Sharma PS. Aripiprazole-induced tardive dystonia. Prim Care Companion J Clin Psychiatry. 2006;8(6):378-379.

67. Duggal HS. Aripiprazole-induced improvement in tardive dyskinesia. Can J Psychiatry. 2003;48(11):771-772.
68. Sharma A, Ramaswamy S, Dewan VK. Resolution of ziprasidone-related tardive dyskinesia with a switch to aripiprazole. Prim Care Companion J Clin Psychiatry. 2005;7(1):36.

69. Kane JM, Barnes TR, Correll CU, et al. Evaluation of akathisia in patients with schizophrenia, schizoaffective disorder, or bipolar I disorder: a post hoc analysis of pooled data from short- and long-term aripiprazole trials. J Psychopharmacol. 2010;24(7):1019-1029.

70. Kane JM, Fleischhacker WW, Hansen L, Perlis R, Pikalov A 3rd, Assunção-Talbott S. Akathisia: an updated review focusing on secondgeneration antipsychotics. J Clin Psychiatry. 2009;70(5):627-643.

71. Furuse T, Hashimoto K. Fluvoxamine for aripiprazole-associated akathisia in patients with schizophrenia: a potential role of sigma-1 receptors. Ann Gen Psychiatry. 2010;6:11.

72. Ramaswamy S, Vijay D, William M, Sattar SP, Praveen F, Petty F. Aripiprazole possibly worsens psychosis. Int Clin Psychopharmacol. 2004; 19(1):45-48.

73. Barnas ME, Hussain N, Petrides G. Treatment-emergent psychosis with aripiprazole. J Clin Psychiatry. 2005;66(10):1339.

74. Reeves RR, Mack JE.Worsening schizoaffective disorder with aripiprazole. Am J Psychiatry. 2004;161(7):1308.

75. Grover S, Sharan P, Gupta N. Aripiprazole worsens psychosis: a case report. Prim Care Companion J Clin Psychiatry. 2006;8(6):380-381.

76. Ahuja N, Lloyd AJ. Aripiprazole and worsening of psychosis: a case report. J Clin Psychiatry. 2007;68(5):805-806.

77. Ahuja N, Lloyd AJ. Worsening of psychosis in a 30 year old man with undifferentiated schizophrenia. Ann Clin Psychiatry. 2008; 20(2):113-114.

78. Kapusta ND, Mossaheb N, Barnas C, Fischer P. Aripiprazole-induced psychosis: a case report of reexposure by stepwise up-titration. J Clin Psychiatry. 2007;68(9):1445-1446.

79. Letmaier M, Painold A, Holl AK, Grohmann R, Vergin H. Severe psychotic exacerbation during combined treatment with sripiprazole/ haloperidol after prior treatment with risperidone. Int J Psychiatry Clin Pract. January 3, 2012. [Epub ahead of print.]

80. Padala PR, Wengel SP, Petty F. Manic episode during treatment with aripiprazole. Am J Psychiatry. 2007;164(1):172-173.

81. Traber R, Schneiter R, Modestin J. A case of aripiprazole-induced mania. Pharmacopsychiatry. 2007;40(1):37-38.

82. Donohue A. First manic episode in a 55-year-old man after initiation of aripiprazole. Psychiatry. 2010;7(4):37-39.

83. Benyamina A, Samalin L. Atypical antipsychotic-induced mania/ hypomania: a review of recent case reports and clinical studies. Int $J$ Psychiatry Clin Pract. 2012;16(1):2-7.

84. Holzer L, Eap CB. Aripiprazole and suicidality. Int Clin Psychopharmacol. 2006;21(2):125-126.

85. Selvaraj V, Ramaswamy S, Sharma A, Wilson D. New-onset psychosis and emergence of suicidal ideation with aripiprazole. Am J Psychiatry. 2010;167(12):1535-1536.

86. Beers E, Loonen AJ, Van Grootheest AC. Suicidal ideations and suicide attempts after starting on aripiprazole, a new antipsychotic drug. Ned Tijdschr Geneeskd. 2006;150(7):401-402. Dutch.

87. Rosenheck RA. Aripiprazole and perphenazine: no difference. J Clin Psychiatry. 2007;68(11):1812-1813.

88. Duggal HS, Mendhekar DN. High-dose aripiprazole in treatmentresistant schizophrenia. J Clin Psychiatry. 2006;67(4):674-675.

89. Hughes D, Morcos M. Use of aripiprazole in treatment resistant schizophrenia. J Psychopharmacol. 2008;22(8):927-928.

90. Jong-Yih L. Successful switch from clozapine to aripiprazole. A case report. J Clin Psychopharmacol. 2009;29(1):93-95.

91. Spina E, de Leon J. Metabolic drug interactions with newer antipsychotics: a comparative review. Basic Clin Pharmacol Toxicol. 2007;100(1):4-22.

92. Urichuk L, Prior TI, Dursun S, Baker G. Metabolism of atypical antipsychotics: involvement of cytochrome P450 enzymes and relevance for drug-drug interactions. Curr Drug Metab. 2008;9(5):410-488. 
93. Lim S, Pralea C, Schnitt J, Bowers MB Jr, Cooper C. Possible increased efficacy of low-dose clozapine when combined with aripiprazole. J Clin Psychiatry. 2004;65(9):1284-1285.

94. Ashton AK. Aripiprazole augmentation of clozapine: in refractory schizophrenia. Psychiatry. 2005;2(2):18-19.

95. Ziegenbein M, Sieberer M, Calliess IT, Kropp S. Combination of clozapine and aripiprazole: a promising approach in treatment-resistant schizophrenia. Aust N Z J Psychiatry. 2005;39(9):840-841.

96. Abu-Tair F, Kopitz J, Bergemann N. Clozapine augmented with aripiprazole in 5 patients with schizophrenia. J Clin Psychopharmacol. 2006;26(6):669-671.

97. Clarke LA, Lindenmayer JP, Kaushik S. Clozapine augmentation with aripiprazole for negative symptoms. J Clin Psychiatry. 2006;67(4):675-676.

98. Stoner SC, Dahmen MM, Berges A, Petry WM. Augmentation of aripiprazole with low-dose clozapine. Pharmacotherapy. 2007;27(11): 1599-1602.

99. Mossaheb N, Spindelegger C, Asenbaum S, Fischer P, Barnas C. Favourable results in treatment-resistant schizophrenic patients under combination of aripiprazole with clozapine. World J Biol Psychiatry. 2010;11(2):502-505.

100. Henderson DC, Kunkel L, Nguyen DD, et al. An exploratory openlabel trial of aripiprazole as an adjuvant to clozapine therapy in chronic schizophrenia. Acta Psychiatr Scand. 2006;113(2):142-147.

101. Ziegenbein M, Wittmann G, Kropp S. Aripiprazole augmentation of clozapine in treatment-resistant schizophrenia: a clinical observation. Clin Drug Investig. 2006;26(3):117-124.

102. Karunakaran K, Tungaraza TE, Harborne GC. Is clozapine-aripiprazol combination a useful regime in the management of treatment-resistant schizophrenia? J Psychopharmacol. 2007;21(4):453-456.

103. Mitsonis CI, Dimopoulos NP, Mitropoulos PA, et al. Aripiprazole augmentation in the management of residual symptoms in clozapinetreated outpatients with chronic schizophrenia: An open-label pilot study. Prog Neuropsychopharmacol Biol Psychiatry. 2007;31(2): 373-377.

104. De Risio A, Pancheri A, Simonetti G, Giannarelli D, Stefanutto L, Gentile B. Add-on of aripiprazole improves outcome in clozapineresistant schizophrenia. Prog Neuropsychopharmacol Biol Psychiatry. 2011;35(4):1112-1116.

105. Chang JS, Ahn YM, Park HJ, et al. Aripiprazole augmentation in clozapine-treated patients with refractory schizophrenia: an 8-week, randomized, double-blind, placebo-controlled trial. J Clin Psychiatry. 2008;69(5):720-731.
106. Fleischhacker WW, Heikkinen ME, Olie J-P, et al. Effects of adjunctive treatment with aripirazole on body weight and clinical efficacy in schizophrenia patients treated with clozapine: a randomized, double-blind, placebo-controlled trial. Int J Neuropsychopharmacol. 2010;13(8):1115-1125.

107. Barbui C, Accordini S, Nose M, et al. Aripiprazole versus haloperidol in combination with clozapine for treatment-resistant schizophrenia in routine clinical care. J Clin Psychopharmacol. 2011;31(3): 266-273.

108. Muscatello MR, Bruno A, Pandolfo G, et al. Effect of aripiprazole augmentation of clozapine in schizophrenia: a double-blind, placebocontrolled study. Schizophr Res. 2011;127(1-3):93-99.

109. Benedetti A, Di Paolo A, Lastella M, et al. Augmentation of clozapine with aripiprazole in severe psychotic bipolar and schizoaffective disorders: a pilot study. Clin Pract Epidemiol Ment Health. 2010;6:30-35

110. Englisch S, Zink M. Combined antipsychotic treatment involving clozapine and aripiprazole. Prog Neuropsychopharmacol Biol Psychiatry. 2008;32(6):1386-1392.

111. Lieberman JA, Safferman AZ, Pollack S, et al. Clinical effects of clozapine in chronic schizophrenia: response to treatment and predictors of outcome. Am J Psychiatry. 1994;151(12): 1744-1752.

112. Meltzer HY, Bastani B, Kwon KY, Ramirez LF, Burnett S, Sharpe J. A prospective study of clozapine in treatment-resistant schizophrenic patients. I. Preliminary report. Psychopharmacology (Berl). 1989;99 Suppl:S68-S72.

113. Jones PB, Barnes TR, Davies L, et al. Randomized controlled trial of effect on quality of life of second- vs first-generation antipsychotic drugs in schizophrenia. Cost Utility of the Latest Antipsychotic Drugs in Schizophrenia Study (CUtLASS 1). Arch Gen Psychiatry. 2006;63(10):1079-1087.

114. Cobo Gómez JV, Fuste G, Coronas R, et al. Combination of aripiprazole and other psychopharmacological treatments in resistant- and multi-resistant patients. Curr Drug Saf. 2008;3(3): 210-215.

115. Kane JM, Correll CU, Goff DC, et al. A multicenter, randomized, double-blind, placebo-controlled, 16-week study of adjunctive aripiprazole for schizophrenia or schizoaffective disorder inadequately treated with quetiapine or risperidone monotherapy. J Clin Psychiatry. 2009;70(10):1348-1357.
Neuropsychiatric Disease and Treatment

\section{Publish your work in this journal}

Neuropsychiatric Disease and Treatment is an international, peerreviewed journal of clinical therapeutics and pharmacology focusing on concise rapid reporting of clinical or pre-clinical studies on a range of neuropsychiatric and neurological disorders. This journal is indexed on PubMed Central, the 'PsycINFO' database and CAS.

\section{Dovepress}

The manuscript management system is completely online and includes a very quick and fair peer-review system, which is all easy to use. Visit http://www.dovepress.com/testimonials.php to read real quotes from published authors. 